\title{
How Weather Factors Affect Electricity Consumption in the Different Times Ranges: A Study in the Bangkok Metropolitan Region of Thailand
}

\author{
Yada Ratanawaraha, Tikhamporn Kaewkitipong, Sirapob Nardviriyakul, and Jing Tang
}

\begin{abstract}
This paper analyses how weather factors affect electricity consumption in different time ranges in the Bangkok metropolitan region of Thailand. To answer this question, we use every 30-min data from 2015 to 2017 to discover the relationship between the electricity consumption and seven weather factors including temperature, dew point, relative humidity, wind (quantity), pressure, rainfall and, cloud using Pearson correlation. While the majority of people tend to think that temperature is the factor that contributed to load the most, our statistical result shows that temperature only affects electricity consumption in the very short term (within one day). In the weekly and monthly range, the electricity load is mainly associated with dew point. Hence, in different time ranges, different weather and climate factors contribute to electricity load. It suggests that future research and practice to choose carefully the factors in terms of electricity consumption prediction in different time ranges.
\end{abstract}

Index Terms-Dew point, electricity consumption, relative humidity, wind.

\section{INTRODUCTION}

Thailand is a country located on the equator with the total area around 200,000 square miles. The boundaries of Thailand with adjacent areas in the northern side are Myanmar and Laos, in the Eastern side are Laos, Cambodia and the Gulf of Thailand, in the Southern side is Malaysia and in the Western side are Myanmar and the Andaman Sea [1].

According to the climate pattern and geography conditions, Thailand is divided into five parts including Northern, Northeastern, Central, Eastern, and Southern Parts. The topography of each part is entirely different. In Central part, which is the focus of this study, contains of 18 provinces including Nakhon Sawan, Uthai Thani, Chai Nat, Sing Buri, Lop Buri, Ang Thong, Sara Buri, Suphan Buri, Ayutthaya, Pathum Thani, Kanchanaburi, Ratchaburi, Nakhon Pathom, Nonthaburi, Bangkok Metropolis, Samut Prakan, Samut Sakhon and Samut Songkhram. This part is a sizeable low-level plain where the Ping, Wang, Yom, and Nan Rivers originated in the Northern Part join together to be the Chao Phraya River at Nakhon Sawan province. On the other hand, the western mountains in the Northern Part extend to this part along the western portion.

The climate of Thailand is affected by monsoon. In mid-May, the southwest monsoon brings a stream of warm

Manuscript received February 25, 2019; revised May 13, 2019.

The authors are with Sirindhorn International Institute of Technology, Thailand (e-mail: ratanawaraha.yada@gmail.com, t.kaewkitipong@gmail.com, acrebcc@gmail.com, tangjing@siit.tu.ac.th). moist air from the Indian Ocean to Thailand causing abundant rain over the country until mid-October.

The northeast monsoon usually starts in mid-October brings the cold and dry air from the anticyclone in Mainland China over major parts of Thailand until mid-February. From mid-February to mid-May is a pre-monsoon season. It is the transitional period from the northeast to southwest monsoon and the weather becomes warmer. April is the hottest month.

Cloud cover is usually few from November to March. Extreme temperatures usually occur when perfectly clear skies found. Cumulus and Cumulonimbus rarely found because most cloud in this period is high clouds. Most clouds in the sky are convective clouds during the southwest monsoon [1].

As a matter of fact, nowadays a trend in electricity consumption is very significant and widespread use. Furthermore, global warming is considered as one of the most important factors which caused by climate change. To study of how climate change effect to the electricity consumption that people use in their everyday life, would be not only answering our assumption but also further the knowledge to others field of education such as consumer behavior, environment, weather forecasting, and electricity supply and demand forecasting.

The research paper aims to explore the potential weather factors toward electricity consumption and look into what are the factors that affect daily, weekly, and monthly electricity consumption.

\section{LITERATURE REVIEW}

The research about the relationship between climate change and electricity consumption has long been studied. The impact on the electricity demand for heating and cooling has been most studied. There is an idea that said that climate change plays an important role in electricity consumption behavior and changes in the load of the network. Meanwhile, the most important factor cannot be anything but temperature because the use of electricity for heating and cooling devices is very large scale [2].

According to Marie Bessec and Julien Fouquau previous research, the temperature is a major determinant of electricity consumption in 15 European countries. The sample countries consist of Austria, Belgium, Denmark, Finland, France, Germany, Greece, Ireland, Italy, Luxembourg, the Netherlands, Portugal, Spain, Sweden, and the United Kingdom. The demand for electricity and temperature are expected not to linked in winter. As some group of the sample 
can decrease electricity consumption by using other energy resources to produce heat. However, in summer, as temperature increases, it leads to an increase in the demand for electricity through air condition and cooling devices. This phenomenon is called the cooling effect [3].

Both of policymaking and planning future investment have a significant relationship to forecasts of electricity demand. Moreover, as rapid population growth, economic growth, and an uncertain regulatory environment and the threat of significant global climate change effect to the long-term planning of electricity supply according to Aroonruengsawat and Auffhammer research [4]. From the past, forecasting electricity demand has played an important role in changing technology, prices, net income, and the growth of population. Energy consumption significantly increased by global warming said by Cline [5]. Mideksa and Kallbekken's research mentioned that electricity demand and supply will be affected by climate change through energy market. Climate change has a strong influence on the energy part. So, the most critical threat is the policy response to climate change [6].

During higher temperature, cooling demand is increased, heating demand is decreased, and to reduce electricity production from thermal power plants. The impact on climate change in term of the supply of electricity from non-thermal sources represents geographical variability according to diversity in a desire to change precipitation and temperature. The report also mentioned that electricity has been used in a number of purposes for households and businesses. To exemplify the point, heating and air conditioning, lighting, cooking and operating equipment. Even if there are some aspects of the electricity uses that do not have a correlation with climate change such as cooking. Whereas, heating and air conditioning are directly related to climate and weather [6].

Households and firms tend to consume more energy in the form of electricity, gas, and oil during warmer summers and cooler winters. Furthermore, the electricity consumption on cooling is increased due to climate change while the use of other fuels for heating is reduced [7].

Natural gas and electricity demand are statistically responsive to changes in the weather. Whereas gasoline and jet fuel demand have no significant effect from changes in heating and cooling degree days according to Considine's research [8].

The peak electricity consumption will increase by 1.5 to $2 \%$ for every $1^{\circ} \mathrm{F}$ increase in temperature if the population is more than 100,000 . However, during the last 40 years the temperatures in an urban area during summer afternoons in the US cities have increased by 2 to $4^{\circ} \mathrm{F}$, so they concluded that the heat island effects are compensated due to increase in urban electricity demand of 3 to $8 \%$ [9].

\section{RESEARCH DESIGN AND METHODOLOGY}

\section{A. Data Collection}

Electricity Generating Authority of Thailand (EGAT) provides us the data including date, time, load $(\mathrm{KwH})$, temperature $\left({ }^{\circ} \mathrm{C}\right)$, dew point $\left({ }^{\circ} \mathrm{C}\right)$, relative humidity $(\%)$, wind(mph), pressure $(\mathrm{Pa})$, rainfall $(\mathrm{mm})$, cloud (level) and peak load $(\mathrm{KwH})$ between year 2015-2017. The data is collected in the base of every 30 minutes or 48 records a day. All the data collected by the sensor in a different location. There are many missing data. In 2015, every month have missing data at least 3 days but especially in April to July have missing data more than 10 days in a month. So, we choose to ignore these months. Also, in December 2016, the data missing up to 11 days, so we choose to ignore this month. In 2017, the data was collected only 6 months from January to June but after that, no data was collected so we decide to ignore all uncollected data.

\section{B. Data Description}

This part is composed of line graphs indicate the data that provide information in various aspects such as total peak loads, wind speed, Average Dewpoint, Average Relative Humidity, Average Temperature, Average Pressure, Average Rainfalls and level of cloudiness from January 2015 - June 2017
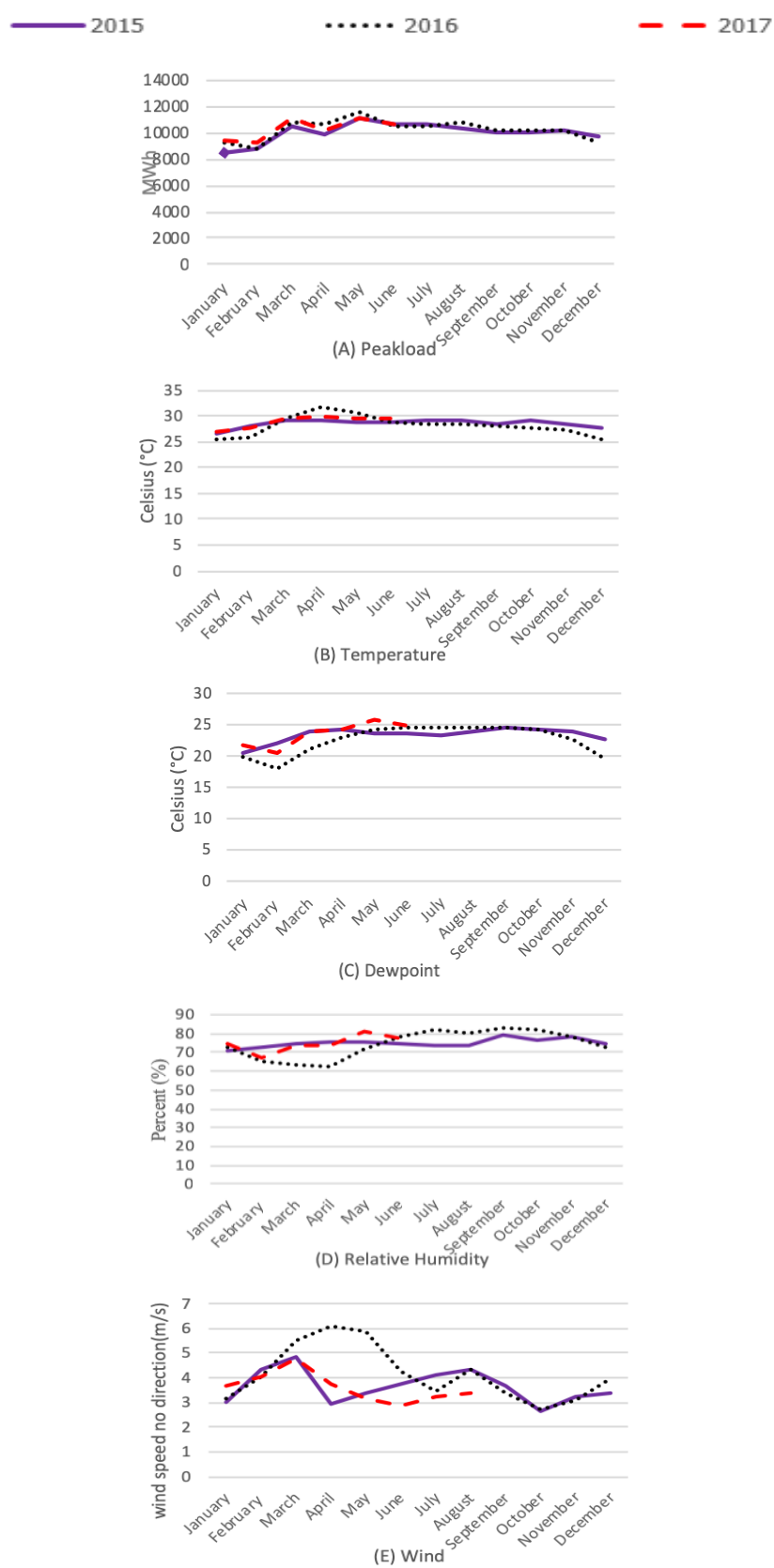

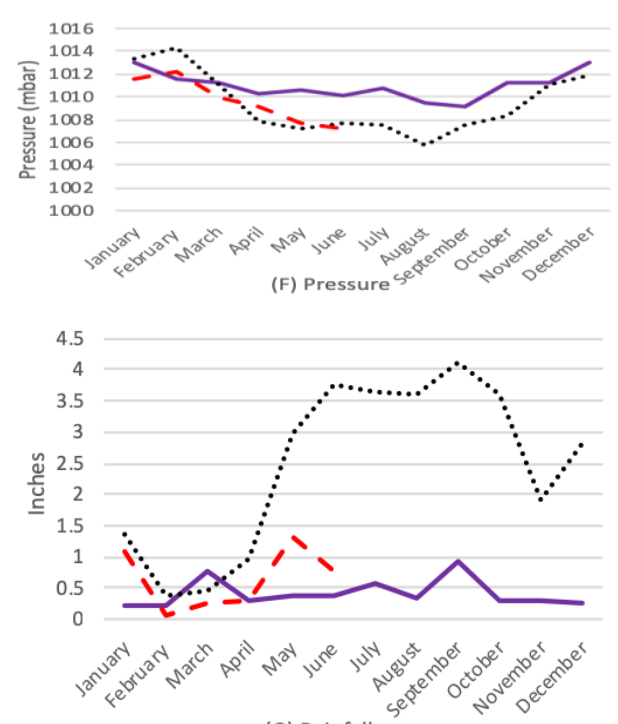

(G) Rainfalls

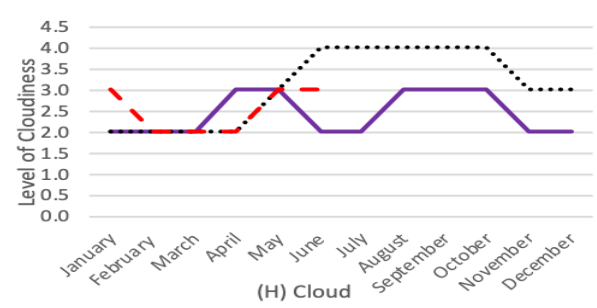

Fig. 1. Data description.

In Fig. 1-a, the graph represents the total peak loads. The total peak loads tend to be lowest in January at 8,459.47MWh due to a long holiday period as most of the industry shut down for their New year vacation. The trend starts to considerably increase and reach its highest at 11,651.67 MWh in May then it is gradually decreased and stabilized throughout the year.

In Fig. 1-b, the graph represents the average temperature. It is obvious to see that in 2016 , the temperature rose to the highest point at $31.66^{\circ} \mathrm{C}$ in April and decrease to $17.95^{\circ} \mathrm{C}$, which is the lowest point. While in the year 2015 and 2017, they are both stables throughout the year. The reason why the temperature in Thailand is not varied because of the seasonal in Thailand is different from the European country as our country is mostly in summer and rainy season.

In Fig. 1-c, it illustrates the amount of Dew point. There was a gradual rise in the first quarter of the year. This trend has been the same for 3 years in 2015, 2016 and 2017. Moreover, this figure is related to figure 2 as Dew point directly related to the temperature. If the dew point increased

In Fig. 1-d, the graph represents average Relative Humidity, which is the ratio of the partial pressure of water vapor to the equilibrium vapor pressure of water at a given temperature. The highest point is in September 2016 at 82.54 percent and the lowest point in April 2016 at 62.55 percent. In 2016, there was a gradually drop from February to April and slightly grew and stable from June to December.

In Fig. 1-e, it illustrates the amount of wind speed no direction. In 2016, there was a significantly rose to its highest point at $6.10 \mathrm{~m} / \mathrm{s}$ due to the monsoon period in April and steadily drop in June. Whereas, the lowest wind speed at 2.66 $\mathrm{m} / \mathrm{s}$ occurred in October 2015.

In Fig. 1-f, the graph represents the pressure of air. The graph significantly shows a U- shape curve. The pressure of air in 2015 was more than in 2016 and 2017. In 2016, there was a substantial drop from its highest point at 1,014 Mbar in February and reach its lowest point at 1,005.72 Mbar in August 2016 the gradually climbed up. The average which has the highest point in February 2016 at 1,014.27Mbar and lowest point in August 2016 at 1,005.72Mbar.The pressure trend in 2015 seems to be higher than in 2016 and 2017.

In Fig.e 1-g, represent the average of rainfalls. The trend in 2016 is significantly different from 2015 and 2017. The trend in 2016 sharply grew in May 2016 and reach its peak at 4.3 inches in September 2016 while the lowest at 0.08 inches in 2017 was on February which implied that there was a large amount of rainfall in 2016 whereas, there were a few rainfalls in 2015 and 2017 as seen by the trend of the graph that nearly reaches the lowest point.

In Fig. 1-h, the graph represents the level of cloudiness in each month which separates into six levels consist of level 1 (no cloud at all), Level 2 (very clear), level 3 (partially cloudy), level 4 (mostly cloudy), level 5 (cloudy) and level 6 (very cloudy). It is apparently clear that there is a large amount of cloud in 2016 than in 2015 and 2017 as a trend steeply rose up in April 2016 and the trend reach its maximum, which is very cloudy in June 2016 then remain constant and start to decrease in October 2016 at the end of rainy. Whereas, in 2015 and 2017, the level of cloudiness is very similar to the highest level of cloudiness.

\section{DATA ANALYSIS}

Before performed the regression, we need to check whether all forecasting variables are independent. Correlation is the statistical technique that shows whether and how strongly pairs of variables are related. The significance result of a correlation is called "Correlation Coefficient" or " $r$ ". It ranges from -1.0 to +1.0. In 1996, Evans [10] suggests for the absolute value of $r$ as following;

TABLE I: EVANS ABSOLUTE VALUE OF
\begin{tabular}{|c|c|}
\hline $\begin{array}{c}\text { Size of } \\
\text { correlation }\end{array}$ & $\begin{array}{c}\text { Interpretatio } \\
\mathbf{n}\end{array}$ \\
\hline $0.00 \leq r<0.20$ & Very weak \\
\hline $0.20 \leq r<0.40$ & Weak \\
\hline $0.40 \leq r<0.60$ & Moderate \\
\hline $0.60 \leq r<0.80$ & Strong \\
\hline $0.80 \leq r<1.00$ & Very strong \\
\hline
\end{tabular}

The direction of the relationship is indicated by the sign of the coefficient; a + sign indicates a positive relationship and a - sign indicates a negative relationship and the closer $r$ is to -1.0 or +1.0 , the more two variables are related.

A Pearson correlation coefficient [11] is a method use for measuring the linear relationship between two random variables. It is used to indicate the relationship between temperature, dew point, relative humidity and wind vary with load forecasting categories; very short-term (periodically and daily), short-term (weekly) and medium-term load forecasting (monthly) as shown in Table II. 
TABLE II: CORRELATION RESULT

\begin{tabular}{|c|c|c|c|c|c|c|c|c|c|c|c|c|c|c|c|c|c|c|c|c|c|}
\hline \multirow{6}{*}{$\overline{\bar{~}}$} & $\$$ & & & & 7 & 主 & & & & - & $\xi$ & & & & - & 5 & & & & - & \\
\hline & 到 & & & - & : & 固 & & & - & 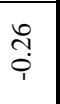 & $\approx$ & & & & 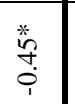 & 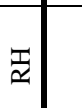 & & & - & & \\
\hline & ิे & & - & 荌 & $\stackrel{\infty}{9}$ & - & & - & $\begin{array}{l}0 \\
\stackrel{0}{0}\end{array}$ & $\begin{array}{l}\text { Î } \\
\text { Q }\end{array}$ & 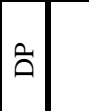 & & - & & 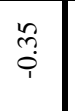 & aิ & & - & $\mid$\begin{tabular}{c}
$*$ \\
\multirow{2}{*}{} \\
$\infty$ \\
0 \\
0
\end{tabular} & 蒡 & \\
\hline & $H$ & - & 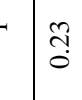 & $\begin{array}{l}* \\
\stackrel{*}{*} \\
\stackrel{i}{i}\end{array}$ & : & $H$ & - & | & $\begin{array}{l}\Delta \\
\dot{0} \\
0\end{array}$ & $\begin{array}{l}\infty \\
0 \\
0 \\
0\end{array}$ & $H$ & & $\begin{array}{l}\stackrel{*}{*} \\
\stackrel{2}{o} \\
0\end{array}$ & ํํ & $\stackrel{\circ}{i}$ & $H$ & - & $\mid \begin{array}{c}* \\
\dot{*} \\
0 \\
0 \\
0\end{array}$ & \begin{tabular}{|l|}
\multirow{7}{*}{} \\
\\
\end{tabular} & $\frac{n}{9}$ & \\
\hline & - & 卷 & \begin{tabular}{l|c}
0 \\
$\vdots$ \\
0
\end{tabular} & \begin{tabular}{l}
$*$ \\
\multirow{4}{*}{} \\
$\vdots$ \\
\end{tabular} & 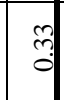 & & $\stackrel{8}{\circ}$ & : & $\begin{array}{l}t \\
0 \\
0\end{array}$ & $\begin{array}{l}8 \\
\stackrel{0}{1} \\
\end{array}$ & \begin{tabular}{|l|l}
- & - \\
\end{tabular} & $-\stackrel{*}{\stackrel{*}{0}}$ & : & ત્. & $\underset{1}{\infty}$ & - & 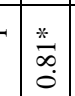 & \begin{tabular}{|c|}
$*$ \\
\multirow{2}{*}{} \\
0 \\
0 \\
0
\end{tabular} & \begin{tabular}{|l}
$*$ \\
2 \\
2 \\
0 \\
0
\end{tabular} & $\frac{n}{i}$ & \\
\hline & & H & ฉิ & $\frac{\pi}{2}$ & 3 & ــ & $H$ & $\tilde{\Omega}$ & $\underset{\simeq}{\simeq}$ & $\Sigma$ & دـ. & د & aิ & $\stackrel{\mathbb{I}}{\simeq}$ & 3 & دـ. & ג & aे & $\frac{\pi}{\alpha}$ & $\xi$ & \\
\hline \multirow{6}{*}{$\stackrel{\bullet}{\bar{\lambda}}$} & $\$$ & & & & -1 & $\S$ & & & & - & $\xi$ & & & & - & 5 & & & & - & \\
\hline & a & & & - & 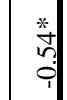 & 弆 & & & - & 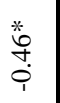 & $\frac{T}{\simeq}$ & & & - & $\begin{array}{l}\text { 苂 } \\
\text { cit } \\
i\end{array}$ & $\widetilde{T}$ & & & - & 倦 & \\
\hline & 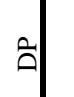 & & & $\mid \begin{array}{l}0 \\
0 \\
0\end{array}$ & $\begin{array}{l}\infty \\
0 \\
:\end{array}$ & ิी & & - & $\begin{array}{l}\text { 茴 } \\
0 \\
0\end{array}$ & $\vec{F}$ & $\tilde{\Delta}$ & & - & $\begin{array}{l}* \\
0 \\
0 \\
0 \\
0\end{array}$ & $\vec{i}$ & aे & & & 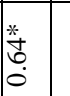 & $\stackrel{t}{0}$ & \\
\hline & $H$ & - & & 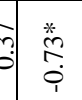 & 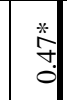 & $H$ & - & | & $\begin{array}{c}\text { tu } \\
\stackrel{i}{1}\end{array}$ & $\vec{m}$ & $H$ & - & $\begin{array}{l}\text { : } \\
\stackrel{*}{0} \\
0 \\
0\end{array}$ & 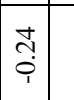 & $\vec{m}$ & $H$ & & 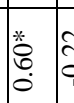 & 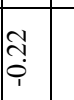 & 晜 & \\
\hline & - & 茴 & $\stackrel{5}{3}$ & 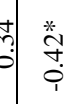 & ? & & $\stackrel{n}{0}$ & ?: & $\begin{array}{l}\stackrel{\partial}{0} \\
\dot{0}\end{array}$ & $\stackrel{7}{0}$ & - & 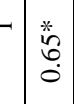 & $\begin{array}{l}\stackrel{*}{*} \\
\stackrel{0}{0} \\
\stackrel{0}{*}\end{array}$ & $=$ & $\stackrel{+}{m}$ & - & $\mid \begin{array}{l}* \\
\infty \\
\infty \\
0 \\
\dot{0}\end{array}$ & 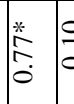 & $\stackrel{9}{\circ}$ & : & \\
\hline & - & $t$ & $-\mid \vec{a}$ & $\frac{T}{\widetilde{s}}$ & 5 & 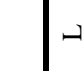 & $H$ & $\tilde{a}$ & $\bar{\Omega}$ & $\xi$ & נـ. & د & ฉิ & $\frac{\pi}{2}$ & 3 & دـ & $A$ & $\tilde{\Omega}$ & $\frac{T}{2}$ & $\xi$ & $\bar{z}$ \\
\hline \multirow{6}{*}{ 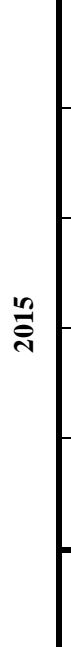 } & $\xi$ & & & & - & 5 & & & & - & $\xi$ & & & & - & $\xi$ & & & & - & \\
\hline & $\stackrel{T}{\simeq}$ & & & - & & $\frac{\pi}{\approx}$ & & & - & $\begin{array}{l}0 \\
\stackrel{0}{1} \\
1\end{array}$ & $\frac{T}{2}$ & & & - & $\stackrel{0}{\stackrel{0}{i}}$ & $\frac{T}{\approx}$ & & & - & $\stackrel{8}{\circ}$ & \\
\hline & ฉิ & & - & 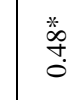 & 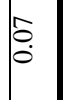 & $\vec{\Delta}$ & & - & $\begin{array}{l}\stackrel{*}{*} \\
\stackrel{0}{0}\end{array}$ & $\stackrel{8}{\circ}$ & $\tilde{a}$ & & - & \begin{tabular}{|l|}
$*$ \\
$\dot{\alpha}$ \\
0 \\
0
\end{tabular} & $\stackrel{\infty}{0}$ & aิ & & $-\frac{*}{2}$ & 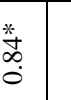 & તิ & $\begin{array}{l}\overline{\mathscr{\Xi}} \\
\text { II }\end{array}$ \\
\hline & $H$ & & $-m_{0}^{m}$ & : * & 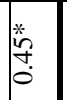 & $H$ & - & $\mid$\begin{tabular}{l}
$*$ \\
\multirow{2}{*}{} \\
$\stackrel{0}{0}$
\end{tabular} & $\frac{n}{0}$ & $\stackrel{ \pm}{ \pm}$ & $H$ & - & $\begin{array}{l}\stackrel{*}{0} \\
\stackrel{0}{0}\end{array}$ & 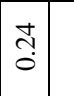 & $\stackrel{\circ}{\circ}$ & $H$ & & \begin{tabular}{ll}
$*$ \\
\multirow{6}{*}{} \\
0 \\
0
\end{tabular} & तે & సิ & 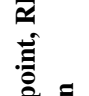 \\
\hline & - & $b^{*}$ & $\vec{\jmath}$ & के & m. & - & $\bar{m}$ & $\mid$\begin{tabular}{c}
$\mid$ \\
\multirow{3}{0}{} \\
\end{tabular} & $=$ & $\stackrel{\infty}{\circ}$ & - & $-\quad$\begin{tabular}{l}
$*$ \\
\multirow{7}{*}{} \\
0 \\
0
\end{tabular} & 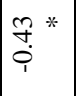 & 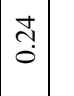 & $\stackrel{0}{0}$ & - & 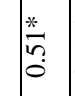 & 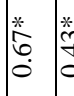 & 范 & ְ̊. & 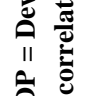 \\
\hline & 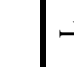 & $\mathrm{H}$ & $-\tilde{a}$ & $\frac{T}{a}$ & 3 & ــ & $H$ & $\vec{a}$ & $\stackrel{T}{\simeq}$ & $\xi$ & دـ & د & aิ & $\frac{T}{\approx}$ & 3 & & $\rightarrow H$ & aे & $\frac{T}{\approx}$ & $\xi$ & $\bar{E}$ \\
\hline \multicolumn{6}{|c|}{ 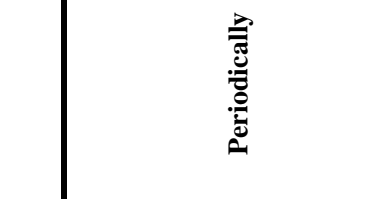 } & \multicolumn{5}{|c|}{ 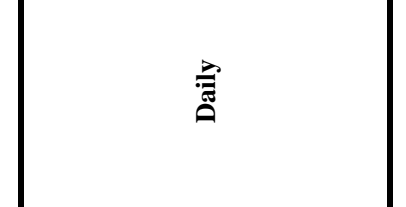 } & \multicolumn{5}{|c|}{ 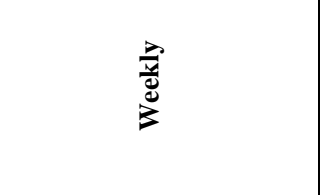 } & \multicolumn{5}{|c|}{ 竞 } & 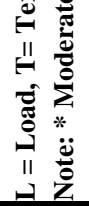 \\
\hline
\end{tabular}

\section{DISCUSSION, CONCLUSION AND LIMITATION}

Weather is the most important independent variable for load consumption in the Bangkok metropolitan region of Thailand. As Fahad and Arbab [12] mentioned, the impact of climate is most noticeable for agrarian and household customers, but it can moreover alter the stack profile of 
industrial customer. From the result, temperature and dew point are the most significant factor for periodically, weekly, and monthly electricity consumption. Moreover, for 2015 periodically, monthly and 2017 monthly also have relative humidity as a significant factor. The statistical result of this study can be used to support the result of [11] which explain the relationship between temperature and dew points. To conclude, temperature and dew point are the most significant variables for periodically, weekly and monthly electricity consumption.

This research methodology can be used for further study in term of electricity consumption forecasting. However, there are also some limitations to this research. First, there are other variables apart from temperature, dew point, relative humidity and wind which are not significant in the correlation analysis such as pressure, rainfall and, cloud. Moreover, the result from this research may not be $100 \%$ accurate since some of the data in this research are the average number calculated using Pivot Table from Microsoft Excel.

\section{CONFLICT OF INTEREST}

The authors declare no conflict of interest.

\section{AUTHOR CONTRIBUTIONS}

Y.R.; Design the study and analyzed the data and worked on the manuscript. T.K. and S.N.; contributed the research and co-wrote the paper. J.T.; contributed the research and aided in interpreting the results. All authors had approved the final version.

\section{REFERENCES}

[1] Climatological Group, Meteorological Development Bureau, Meteorological Department. (2015). The climate of Thailand. [Online] Available: https://www.tmd.go.th/en/archive/thailand_climate.pdf

[2] A. A. Salehizade et al., "Analysis of temperature changes on electricity consumption in Fars Province," Mediterranean Journal of Social Sciences, 2015, vol. 6, no. 3, pp. 610-17.

[3] M. Bessec and J. Fouquau, "The non-linear link between electricity consumption and temperature in Europe: A threshold panel approach," Journal of Economic Literature, 2007.

[4] A. Aroonruengsawat and M. Auffhammer, "Impacts of climate change on residential electricity consumption: Evidence from billing data," The Economics of Climate Change: Adaptations Past and Present, University of Chicago Press, 2011, pp. 311-342.

[5] W. R. Cline, The Economics of Global Warming, New York: Columbia University Press, 1992.

[6] T. K. Mideksa and S. Kallbekken, "The impact of climate change on the electricity market: A review," Energy Policy, 2010, vol. 38, no. 7, pp. 3579-585.

[7] E. T. Mansur, R. Mendelsohn, and W. Morrison, "Climate change adaptation: A study of fuel choice and consumption in the US energy sector," Journal of Environmental Economics and Management, 2008, vol. 55, pp. 175-93.

[8] T. J. Considine, "Markup pricing in a short-run model with inventories," International Society for Inventory Research, ASSA Meetings in Boston, Jan 2000, Massachusetts.

[9] H. Akbari et al., "Cooling our communities - A guidebook on tree planting and light colored surfacing," US Environmental Protection Agency, Office of Policy Analysis, Climate Change Division, Jan 1992.

[10] A. Beldjazia and D. Alatou, "Precipitation variability on the massif forest of mahouna (North Eastern-Algeria) from 1986 to 2010," International Journal of Management Sciences and Business Research, 2016, vol. 5, no. 3.

[11] M. H. Kutner et al., Applied Linear Statistical Models, Boston: McGraw-Hill

[12] M. U. Fahad and N. Arbab, "Factor affecting short term load forecasting," Journal of Clean Energy Technologies, 2014, vol. 2, no. 4, pp. 305-0.

Copyright $(92019$ by the authors. This is an open access article distributed under the Creative Commons Attribution License which permits unrestricted use, distribution, and reproduction in any medium, provided the original work is properly cited (CC BY 4.0).

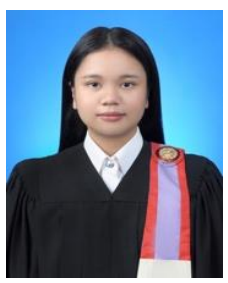

Yada Ratanawaraha was born on 24 January 1997, Bangkok, Thailand. She is currently a fourth-year student, majoring in engineering management at Sirindhorn Institute of Technology, Pathum Thani, Thailand.

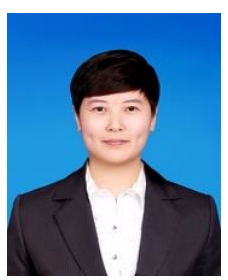

Tikhamporn Kaewkitipong was born on 11 May 1997, Bangkok, Thailand. She is a fourth-year student at Sirindhorn International Institute of Technology, Pathum Thani, Thailand majoring in engineering management.

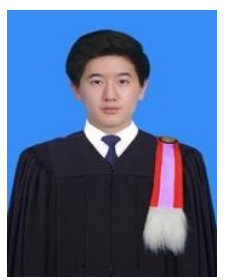

Sirapob Nardviriyakul was born on 9 March 1995, Bangkok, Thailand. He got the bachelor of science in engineering management, Sirindhorn International Institute of Technology, Pathum Thani, Thailand.

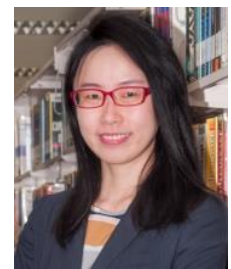

Jing Tang obtained a doctor and master of industrial engineering from Tokyo Institute of Japan.

She is a researcher and a lecturer of School of Management, Sirindhorn International Institute of Technology, Pathum Thani, Thailand. 